Please do not remove this page

RMIT

UNIVERSITY

\title{
Internet content regulation, public drug websites and the growth in hidden Internet services
}

Barratt, Monica; Lenton, Simon; Allen, Matthew

https://researchrepository.rmit.edu.au/esploro/outputs/9921860829301341/filesAndLinks?institution=61RMIT_INST\&index=null

Barratt, M., Lenton, S., \& Allen, M. (2013). Internet content regulation, public drug websites and the growth in hidden Internet services. Drugs: Education, Prevention and Policy, 20(3), 195-202.

https://doi.org/10.3109/09687637.2012.745828

Document Version: Accepted Manuscript

Published Version: https://doi.org/10.3109/09687637.2012.745828

Repository homepage: https://researchrepository.rmit.edu.au

CC BY-NC-ND V4.0

Copyright (C) 2013 Informa UK Ltd.

Downloaded On 2023/04/27 01:30:31 +1000

Please do not remove this page 
Internet content regulation, public drug websites and the growth in hidden Internet services

Accepted 1 Oct 2012 for publication at Drugs: Education, Prevention and Policy

Monica J. Barratt ${ }^{\mathrm{a}}$, Simon Lenton ${ }^{\mathrm{a}}$, Matthew Allen ${ }^{\mathrm{b}}$

anational Drug Research Institute, Curtin University, 54-62 Gertrude Street, Fitzroy, Victoria, 3065, AUSTRALIA

${ }^{\mathrm{b}}$ Department of Internet Studies, Curtin University, Kent Street, Bentley, WA, 6102, AUSTRALIA

Running head: Drug websites and Internet content regulation

Corresponding author

Monica J. Barratt

National Drug Research Institute, Curtin University

54-62 Gertrude Street, Fitzroy, Victoria, 3065, AUSTRALIA

Telephone: +61384138514

Email: m.barratt@curtin.edu.au

Word count (body of paper) $=4647$ (limit 5000) 
Internet content regulation, public drug websites and the growth in hidden Internet services

Governments have traditionally censored drug-related information, both in traditional media and, in recent years, in online media. We explore Internet content regulation from a drugpolicy perspective by describing the likely impacts of censoring drug websites and the parallel growth in hidden Internet services. Australia proposes a compulsory Internet filtering regime that would block websites that 'depict, express or otherwise deal with matters of... drug misuse or addiction' and/or 'promote, incite or instruct in matters of crime'. In this paper, we present findings from a mixed-methods study of online drug discussion. Our research found that websites dealing with drugs, that would likely be blocked by the filter, in fact contributed positively to harm reduction. Such sites helped people access more comprehensive and relevant information than was available elsewhere. Blocking these websites would likely drive drug discussion underground at a time when corporate-controlled 'walled gardens' (e.g., Facebook) and proprietary operating systems on mobile devices may also limit open drug discussion. At the same time, hidden Internet services, such as Silk Road, have emerged that are not affected by Internet filtering. The inability for any government to regulate Tor websites and the crypto-currency Bitcoin poses a unique challenge to drug prohibition policies.

Keywords: harm reduction, censorship, Internet, drug information, drug policy, information control

Abstract word count $=199$ (limit 200) 
Internet content regulation, public drug websites and the growth in hidden Internet services

The Internet is often understood as a democracy-building technology that offers voiceless people the chance to be heard in a public arena (Leaning, 2009). The civil uprisings in the Middle East and North Africa in 2011 demonstrate how Internet-enabled devices can facilitate democratic expression even for people living under restrictive regimes (Al Sharekh, 2011). Yet, around the world, nation states - even those with strong democratic traditions are attempting to implement greater regulation of Internet content (Akdeniz, 2010; Koumartzis \& Veglis, 2011), seeking to manage perceived social ills that might emerge from unfettered online speech. One such form of content is that which relates to illicit drugs. Governments have traditionally sought to limit through censorship the circulation in society of information related to such drugs (Jaehrling, 2010). Attempts to minimise the use of illicit drugs by restrictions on the flow of information about them has already been applied in traditional media (e.g., books, films) but, increasingly in recent years, online media has become a key focus. The Internet has facilitated the sharing of detailed drug-related information and alternative drug policy options by people who are able to remain relatively anonymous (Murguía, Tackett-Gibson, \& Lessem, 2007; Walsh, 2011). However, depending on how authorities categorise these materials, they may be subject to censorship due to their potential to instruct in or incite criminal activity, given the illicit status of the drugs concerned. Such censorship regimes are becoming more common as society's understanding of the Internet matures and governments increasingly find ways to apply equal or stronger restrictions to online speech to those which have applied previously. Additionally, the Internet is now more dominated by so-called 'walled gardens' such as Facebook, in which corporate policies impose limits on speech often more narrow than those established by governments. Finally, the rise of mobile Internet access, through phones and tablet 
computers, also restricts the scope of online drug discussion (Arthur, 2012; Grim, 2010) because of the tendency for people using these devices to rely on 'apps' to access web content in narrow ways, and through more limited channels which favour traditional media outlets. In light of these various developments, in this paper we (1) explore Internet content regulation from a drug-policy perspective by describing the likely impacts on strategies of harm reduction that could result from possible censorship of public drug websites and (2) consider the impacts of the parallel growth in hidden Internet services, including the anonymous online drug marketplace Silk Road where illicit drugs are bought and sold across and within national boundaries.

The Internet and democratic action

As well as being understood as a tool for consuming information and buying products, the Internet has been hailed as a tool for spreading democracy. The Internet is generally understood as "a media form that specifically affords opportunities for the restoration of democracy or of resistance” (Leaning, 2009, p. 105). Leaning locates this claim within two contrasting philosophical frameworks: liberal democratic and radical democratic. Within a liberal democratic framework, the mass media is considered to have a key role in critiquing the activities of the state and guarding the interests of the citizens, while the public sphere constituted through the media is seen as a site for the legitimate expression of opinion. The Internet is seen to offer an opportunity for individuals and organisations, who otherwise lack access to the mass media, to add their voices to public life. In contrast, the radical democratic position contends that, rather than critiquing the activities of government, mass media actually serve to legitimate and reinforce the state and that the public sphere systematically marginalises minority and alternative voices, positioning them as outside of mainstream opinion even when they are permitted to contribute to mass media debates. From this 
perspective, the Internet can be a radical media only if "it affords true anti-systemic action, the articulation of contrary identities and the production of media content outside the normal spheres of action” (Leaning, 2009, p. 106).

Leaning cautioned against non-critical acceptance of the Internet as inherently democratising, yet shows how its use in particular circumstances may enable radical democratic action. The Internet can, if used properly, offer ordinary people a tool through which they can consume, produce and disseminate information that may run counter to dominant discourses, in contrast to traditional forms of mass media where content is centrally produced and distributed to a mass of media consumers. Moreover, this information can be linked closely to action, through fund-raising campaigns, targeted interventions in policy debates, and the production of new discourses which frame issues in more meaningful ways than those found in mass media. Most of all, the Internet is a conversational medium, encouraging users to both produce and consume information, working in either tacit or agreed partnerships and groups ideally to become better informed and then inform others.

The effects of the Internet are not just felt within traditional political domains. The decentralisation of power through Internet usage has also been identified by medical doctors who describe how patients who consult online information about health conditions may be no longer reliant on the doctor as the sole expert, and can become more conscious of their own authority in managing their medical conditions (Eysenbach, 2008). The decentralisation of power and democratisation of information was also described by Bakardjieva (2005) in her ethnography of how people used the Internet in their everyday lives. Most of the people she studied had "become lay researchers willing to make informed decisions on matters of daily life and were aware, thanks to the Internet, of the wide range of alternatives available” (p. 194). Online networks also appear to be more useful for gaining new information than 
physical-community networks, within which social ties are more closely bound (Boase \& Wellman, 2006; Wellman \& Gulia, 1999). This outcome is particularly important where the information sought might, when linked to the person seeking it, cause some negative judgment to be made about that person (as for example in the use of the Internet by young people of alternative sexualities to seek support and advice in 'coming out'; Bond, Hefner, \& Drogos, 2009).

However, as Leaning warns, online participation will not necessarily be part of radical action. The Internet still produces traditional forms of public-sphere engagement (more closely drawing citizens into the normalised debates and discussions articulated within the mass media, which themselves are now heavily invested in Internet distribution). The capacities of the Internet are contingent on societal factors that constrain and enable actions that may contribute to increased participation, power and democracy across citizen groups, including drug users.

The regulation of media content in Australia

Under current Australian law, both traditional and online content can be refused classification and thus, effectively, be prevented from legal circulation (Lumby, Green, \& Hartley, 2009). The content which may thus be censored includes 'instruction on drug use'. The definition of refused classification in the Classification (Publications, Films and Computer Games) Act 1995 (Cth) is broad and relies on an evaluation of whether the material would 'offend against the standards of morality, decency and propriety generally accepted by reasonable adults'. Media that 'depict, express or otherwise deal with matters of... drug misuse or addiction' and/or 'promote, incite or instruct in matters of crime' may be refused classification, subject to the extent to which they would 'offend reasonable adults'. These laws indicate that print 
publications, films, games and online content deemed to instruct in or promote drug use can be currently banned in Australia. For example, the book E for Ecstasy (Saunders, 1993) was seized by Australian customs due to its drug-related content (Saunders, 1997), and PIHKAL: Phenethylamines I Have Known and Loved (Shulgin \& Shulgin, 1992) was also prevented from distribution in Australia (“Expert opinions”, 1997).

In the context of drug prohibition prior to the mid 1990s, many authors who publicly disseminated drug-use instructions did so without identifying themselves in an effort to avoid negative legal and social consequences. For example, instructional materials in cannabis cooking, growing and use were published pseudonymously in the late 1960s and early 1970s, including The Super Grass Grower's Guide by 'Mary Jane Superweed' and The Hashish Cookbook by 'Panama Rose’ (Jaehrling, 2010), while in the 1980s, 'Uncle Fester’ published the infamous Secrets of Methamphetamine Manufacture, which is now in its ninth edition (Fynes-Clinton, 2009). Not long after the public began using the World Wide Web in the mid-1990s, media reports of websites distributing detailed instructions in drug use began to surface (Jenkins, 1999). Early use of the Internet progressed in a largely unregulated fashion, and during this time, many websites that provided detailed instruction in drug use were created (Murguía, Tackett-Gibson, \& Willard, 2007). The Internet has facilitated drug-related publication by enabling anonymous publication; offering the capacity to host sites in countries with less restrictive censorship laws yet still make content available in other countries; and the relative ease and low entry barriers of maintaining websites and participating in collaborative online projects and communities.

While it is still easier to publish online than in print, increased government regulation of Internet content and increased use of proprietary websites and devices have reduced the ease by which instructional drug-related content can be published online. The Australian 
government has proposed legislation mandating that Internet Service Providers (ISPs) block all websites hosting refused classification content (Bennett Moses, 2010). According to the Australian Communications and Media Authority (ACMA), refused classification content includes 'child abuse and child sexual abuse material, depictions of bestiality, material containing excessive violence or sexual violence, detailed instruction in crime, violence or drug use, and/or material that advocates the doing of a terrorist act' (ACMA, 2011, emphasis added). Presently, online content that is brought to the attention of the ACMA can be refused classification, but only websites hosted in Australia can be issued with a notice forcing them to take down that material. Website owners can easily bypass these laws by hosting their websites in other countries with less restrictive laws, though the owners, if resident in Australia, might then be subject to other action (for example under the Crimes Act) for distributing that information. Under the proposed legislation, ISPs would be required to block all websites that contain content that meets the definition of refused classification, regardless of location (Bennett Moses, 2010). Although this policy has principally been promoted to a sceptical public as a method of reducing access to child pornography, it is clear that the legislation would also be used to block drug related information websites (including those focused on harm reduction) and several other kinds of sites whose content is considered by some, but not by any means all, to be offensive (Crawford \& Lumby, 2011; Lumby, et al., 2009).

In addition to government intervention, the increased use of proprietary websites and mobile, 'app' driven devices creates effective, if unintended restrictions on the wide availability of content normally associated with the Internet. For example, both Facebook and Apple have been accused of censorship through removing drug- and sex-related content (Diaz, 2011; Grim, 2010). The increasing popularity of Facebook and Apple products may have reduced 
freedom of expression on the Internet by subjecting content to rules made by corporations (Halliday, 2012). Perhaps more significantly, the rise of Facebook and similar systems which generally involve the clear disclosure of identity make individual efforts to remain completely anonymous more difficult; further, users of mobile devices are less likely (and may even be prevented from) utilising software that renders their activities online technically anonymous.

Notwithstanding these developments, the Internet continues to be used as a tool of subversion, resistance and evasion by people who do not agree with social norms that pathologise drug use (Walsh, 2011). Boyer, Shannon and Hibert's (2005) 'innovative drug users'—who learnt drug practices through websites, applied new knowledge, then disseminated it through online networks — offer an example of folk pharmacologies produced through online communication. In Tackett-Gibson's (2008) analysis of discussion about the drug ketamine in a public online forum, group members debated the validity and the meaning of both the drug experiences of other members and the published research about ketamine risk. These drug users developed their own 'lay person' evaluations of the risks and benefits of ketamine use, with Internet forums providing the means or setting for this to take place. Boyer et al. and Tackett-Gibson's studies indicate that the folk pharmacologies also occur in online environments and are facilitated by the use of online communication technologies. Like Bruns' 'produsers' (2006), these drug users consumed and produced information in a collaborative fashion, not unlike the online collaborators of Wikipedia and Open Source (see Fallis, 2008; Bretthauer, 2002). As in these cases, the intent of these drug users is not explicitly revolutionary in most cases, but, nevertheless, is a radical democratic action because, through the actions of many individuals working together to share information, it undermines the norms of centralised information publication which has previously favoured 
both governments and commercial corporations who have controlled information access and flow to their own ends, if not their own perceived benefit.

Use of the Internet by drug users

Australians' use of illicit drugs cannot help but be influenced by the widespread availability and use of Internet technologies. Australians between 18 and 29 years are the most likely, compared with those younger and older, to have reported illicit drug use in the past 12 months in the most recent National Drug Strategy Household Survey (Australian Institute of Health and Welfare, 2011). The most recent Australian Bureau of Statistics data indicate that these young adults, the most likely to use illicit drugs, also report near universal levels of Internet access: over 90\% of Australians aged 15 to 34 years reported Internet use in 2008-09 and almost all of this use occurred either weekly or daily (Australian Bureau of Statistics, 2011).

People who use drugs are increasingly reporting the Internet as an important source of drugrelated information (Gascoigne, Dillon, \& Copeland, 2004; Johnston et al., 2006). MB’s PhD research involved engagement with the users, moderators and administrators of 40 Internet forums where drugs were discussed in Australia. MB recruited 837 drug users who recently participated in online drug discussion to complete an online survey, and 27 of these respondents also completed in-depth qualitative interviews (Barratt, 2012a). Their median age was 22 years $(M=23.6, S D=6.2$, range $16-51$ years $)$ and $71 \%$ were male $(N=837)$. Over the 18-month data collection period (2007-2008), MB also engaged in online participant observation and saved records of interactions between drug users in public Internet forums. To better understand how forums were run, MB also approached forum 
moderators and administrators and engaged them in discussions about how they deal with drug-related content on their websites.

Harm reduction through online drug discussion

Almost all survey respondents (88\%) reported that they had read or participated in online discussion for the purposes of reducing harm. This category included 'learnt how to use drugs more safely' and 'learnt how to avoid bad experiences with drugs'. A similar proportion of the sample (80\%) reported reading or participating in online discussion for the purposes of enhancing effects. This category included 'learnt ways to enhance drug effects' and 'found out about new ways to get high'. Only 20 respondents who reported seeking information to enhance effects had never engaged in harm reduction. This group represented just 3\% of all respondents who had ever tried to enhance drug effects through online research. These results indicate that Internet forums and the interaction through online communication play an essential role in harm reduction practices by reaching people who seek to enhance their drug use and making safer drug use part of the overall experience which people seek.

Many online interviewees regarded the accessibility of reliable information as the main advantage of online forums. For example, 'collective responses' (more likely to be found online) were given more weight than the opinions of single individuals. Online drug discussion was preferred in contrast to other sources (such as friendship groups), which were usually described as lacking expertise or equivalent experience (e.g., 'Online you can talk to a diversity of people... offline you generally get to talk to some pretty ignorant people'; 'Here are people who have also been through what I have'). Forums provided access to information from a wider variety of people reporting different experiences and opinions, either for the purposes of comparison or because the information sought was only available from a small 
number of people (e.g., 'I could talk to guys in pubs all my life and still never find one person who's heard of 2C-B'). Perhaps the other central advantage of the Internet for discussing drugs was perceived anonymity in finding information, contributing information and interacting with people online. Interviewees described how online drug discussion protected them from divulging their drug use to people in their everyday lives, whom they believed would therefore stigmatise them (e.g., one interviewee said he would be 'scared of people judging' if he were seen 'walking into' a 'centre in the street with all this info').

In terms of which drug practices were affected by online drug discussion, we classified interviewee responses into eight categories (from most to least popular): (1) trying a drug for the first time (including both traditional and novel substances); (2) dosage; (3) content and purity; (4) combining and mixing; (5) settings of use; (6) methods of use; (7) preparing and extracting; and (8) drug sourcing and access. Most interviewees discussed discovering otherwise unknown drugs through the Internet, (e.g., 'It's definitely taught me about some more obscure drugs which has led me to find them and try them'), with these discoveries triggering an interest in trying the drugs. Some interviewees did, however, indicate avoiding particular drugs after researching them online. Only three of 27 interviewees mentioned finding out online how to access drugs.

All public Internet forums we accessed were moderated, usually by volunteers. In some cases, moderators actively promoted harm reduction by emphasising moderate and informed drug taking. In others, any discussion that involved instructions or personal admissions was prohibited (e.g., 'if someone just wants to get high or looking for a quick buzz they get called out pretty quickly'). Moderators also referred forum users to trusted information sources or invited experts (ambulance officers, drug educators) to answer questions. Forum rules also prohibited people using the forums to source drugs and people who did so were usually 
warned or banned from using the forums. In other words, while users of these forums were largely interested in greater knowledge about drug taking, their communications occurred in a setting that encouraged harm reduction.

Likely impacts of blocking public drug websites

Numerous popular international drug websites are likely to be refused classification under the proposed Australian Internet filtering policy. Pillreports.com contains information about the content and purity of pills sold as ecstasy, as well as interaction between users that are instructional or promotional. Drug harm reduction websites, including Erowid.org and Bluelight.ru, contain explicit instructional materials, often from drug users, about the most effective and safest ways to consume drugs, and personal narratives detailing drug experiences designed to assist and educate other drug users. These international sites are not currently affected by Australia’s classification system. If the proposed ISP-level filtering system was adopted however, these sites could be added to the banned list.

Our data suggests that such action, whatever its positive intent, would have negative consequences as drug discussions will be driven from public to private channels of communication, and away from moderated sites which actively encourage harm reduction. Most Australians will have limited or no access to: archives of peer-generated drug information, anonymous social support, official rules and social norms that regulate discussion, and wide and varied voices not otherwise accessible through alternative networks. Equally, blocking websites where people discuss drug use will hamper efforts to monitor drug users, which are currently undertaken by both health and law enforcement agencies, in order to produce interventions that are responsive to new drug trends. This action will also 
remove the possibility of engaging with communities, through their online forms, to produce better public health outcomes (see Barratt \& Lenton, 2010).

Developments in the Australian Internet filter policy

Having already begun regulation of Internet content hosted in Australia in the early 2000s (Allen \& Long, 2004), the Australian government has been pursuing a more aggressive filtering approach to block international content as well. As part of the consultation process about filtering, in 2010, the government delayed introducing the legislation for mandatory ISP-level filtering so as to allow the Australian Law Reform Commission (ALRC) to review the scope of the categories which determine what can and should be censored. In the National Drug Research Institute (2011) submission to the review by the ALRC, we argued that drugrelated content should be understood from a public health perspective, showing how online drug discussion that would be blocked under the proposed filtering policy in fact constituted an effective component of harm reduction approaches and was not, on the whole, directly inciting drug use. Notably, the ALRC study of community attitudes towards media content found that content depicting drug use was rated the least offensive of all potentially banned content they considered (ALRC, 2012). The ALRC recommends that the scope of refused classification of content that 'promotes, incites or instructs in matters of crime' be confined to 'serious crime' and that the category 'detailed instruction in the use of proscribed drugs' be removed altogether. Should the 'refused classification' category remain if or when ISP-level Internet filtering is implemented, the ALRC recommended that only content classified into the most serious categories of sex abuse and violence be filtered (ALRC, 2012). While the review was underway, the three largest ISPs in Australia implemented a voluntary Internet filter that blocks Interpol's blacklist of the "worst of the worst" child abuse websites (Taylor, 2012). As recently as March 2012, Australian Communications Minister Stephen Conroy 
reiterated the government's intent to implement a mandatory filtering system, but it is unclear how the government will respond to the ALRC's recommendations to narrow the definition of refused classification (Taylor, 2012).

The regulation of Internet content in Australia illustrates the intersections between Internet content regulation policy and drug policy, intersections that reflect different understandings of the value and meaning of the circulation of information about drugs, and the benefit of the interaction between people through the Internet. The fluid, conversational nature of online content, and the technical means by which blocking must occur, both tend towards an approach which censors ‘on suspicion’. The classification of specific media products (such as books, films, images) is based on a model where each instance of the material in question could be viewed and judgement made as to its suitability for specific audiences and, importantly, if the social benefit of the material justified circulation. Internet content cannot be accurately conceptualised as one-way or as static, rendering it impossible to assess the content but, instead, requiring that sites of communication and information be refused classification regardless of whether the content actually fits that judgment.

\section{Hidden Internet services}

A consequence of these attempts to regulate the public Internet is movement towards use of private networks and the hidden web. Our data indicate that private or hidden Internet forums were, in the current more permissive regime, seldom used by Internet-savvy drug users in 2007-08. Five years later, drug websites accessible only through the 'dark', 'deep', 'invisible’ or 'hidden' web are now emerging, possibly in part a response to increased surveillance and monitoring of the public forums. Such hidden services are those parts of the Internet that are effectively reached through the use of clients such as Tor (Tor Project, 2011) that anonymise 
the Internet protocol address of the Internet user. Hidden services are not indexed by search engines and are unlikely to be accessed by novice Internet users. These hidden Internet services, along with the emergence of the decentralised international crypto-currency Bitcoin (Bitcoin, 2011), have enabled the building of completely anonymous online marketplaces where illicit drugs are bought and sold across international borders.

Silk Road is the most well-known online marketplace accessed via the hidden web (Barratt, 2012b). Drugs are available for sale under the following categories: ecstasy, cannabis, dissociatives, psychedelics, opioids, stimulants, benzodiazepines and 'other'. Buyers rate sellers and provide comments about the quality of their products, how fast they ship, and their level of professionalism and discretion. These ratings establish the degree of trust that might be assigned to sellers. Silk Road is international in scope, representing buyers and sellers worldwide. Australian drug users and sellers are increasingly utilising Silk Road in order to bring overseas-manufactured drugs into Australia through the postal system and to sell drugs from within Australia to other Australian buyers (Orsmby, 2012). While buying drugs online is not new, Silk Road's use of encrypted electronic currencies and the secrecy afforded by the hidden web increase its attractiveness to drug market participants. That said, Silk Road is not entirely invisible. As discussed below, it serves as an example of how, to avoid some aspects of surveillance, drug websites can combine public communication with secure private communication.

The implications of Silk Road for drug policy

Our preliminary analyses of the Silk Road website and discussion forums provide some evidence that in part the site serves, like the public discussion sites we have also researched, as a way of drug consumers reducing the harm of illicit drugs, particularly if compared to 
street-based drug marketplaces. For example, the forums at the site do include discussion of harm reduction, including resources for people who wish to reduce or eliminate consumption of particular drugs. However, there are more complex elements to Silk Road that also mean its existence is a challenge to our current assumptions about harm reduction, Internet information flows and online drug communities.

The stated intent of Silk Road founders is to challenge drug prohibition. In other words, while serving as a market place, the site also constitutes a form of political action both explicitly and in its attempts to use online technologies to evade closure. In January 2012, Silk Road founder Dread Pirate Roberts posted the first 'State of the Road' address in which he wrote:

It didn’t take long before word got out. Our little hidden market got the attention of the media and soon the politicians and law enforcement. But Silk Road was never meant to be private and exclusive. It is meant to grow into a force to be reckoned with that can challenge the powers that be and at last give people the option to choose freedom over tyranny. We fundamentally believe that people can thrive and prosper under these conditions and so far tens of thousands have done so in the Silk Road market. A revolution has been born.

Observation of the Silk Road forums indicates that many of the site's users also see their participation in the marketplace as a wider protest against drug prohibition which they believe infringes upon their human rights. Silk Road founders and users believe they have the technical architecture necessary to evade law enforcement (through encryption and anonymisation). The use of proxy servers, to disguise the origin of a request for access, also have the effect of mitigating against blocking of the site. 
We have noted the potential harm-reduction elements of Silk Road and its use as a site of resistance against pathologising drug discourses. At the same time, unlike the sites where more public discussion occurs, Silk Road primarily focuses on supply, thus increasing the immediacy with which the 'desire' for a drug promoted through online information can be satisfied. Thus, if Silk Road is exemplary of the only places which could be used for drug discussion, once a filtering approach blocks out those more typically used, then the attempt to block drug-related content online could, in fact, work against harm reduction approaches. 
Acknowledgements of funding and conflict of interest

The National Drug Research Institute at Curtin University is funded by the Australian Government Department of Health and Ageing under the National Drug Strategy. We acknowledge the support and efforts of the online forum users, moderators and administrators who participated in this project. This paper updates and expands on material published in our submission to the ALRC inquiry, also republished in the Australian sector magazines Centrelines and Dovetail in 2011, and presented at the Drugs and Young People conference in Melbourne, 2011, and the Drug Policy Modelling Program Symposium in Sydney, 2012. An earlier version of this paper was presented at the 6th annual meeting, International Society for the Study of Drug Policy, Canterbury, UK, 30-31 May, 2012.

There are no conflicts of interest to report. 
References

Akdeniz, Y. (2010). To block or not to block: European approaches to content regulation, and implications for freedom of expression. Computer Law and Security Review, 26, 260 272.

Al Sharekh, A. (2011). Reform and rebirth in the Middle East. Survival: Global Politics and Strategy, 53(2), 51-60.

Allen, M., \& Long, J. (2004). Domesticating the Internet: Content regulation, virtual nationbuilding and the family. In G. Goggin (Ed.), Virtual nation: The Internet in Australia (pp. 229-240). Sydney, Australia: University of New South Wales Press.

Arthur, C. (2012, April 17). Walled gardens look rosy for Facebook, Apple - and would-be censors. Retrieved from http://www.guardian.co.uk/technology/2012/apr/17/walledgardens-facebook-apple-censors and archived at http://www.webcitation.org/674rQqq9Z

Australian Bureau of Statistics. (2011). Household use of information technology, Australia, 2010-11. Canberra, Australia: Author.

Australian Communications and Media Authority (ACMA). (2011). Online regulation. Canberra, Australia: Commonwealth of Australia. Retrieved from http://www.acma.gov.au/WEB/STANDARD/pc=PC_90169 and archived at http://www.webcitation.org/5y1ckMhsJ

Australian Institute of Health and Welfare. (2011). 2010 National Drug Strategy Household Survey (Drug statistics series no. 25. Cat. no. PHE 145). Canberra, Australia: Author. 
Australian Law Reform Commission (ALRC). (2012). Classification - Content regulation and convergent media. Final report (ALRC Report No. 118). Canberra, Australia: Commonwealth of Australia.

Bakardjieva, M. (2005). Internet society. The Internet in everyday life. London, England: Sage.

Barratt, M. J. (2012a). The efficacy of interviewing young drug users through online chat. Drug and Alcohol Review, 31, 566-572.

Barratt, M. J. (2012b). Silk Road: eBay for drugs [letter to the editor]. Addiction, 107, 683.

Barratt, M. J., \& Lenton, S. (2010). Beyond recruitment? Participatory online research with people who use drugs. International Journal of Internet Research Ethics, 3, 69-86.

Bennett Moses, L. (2010). Creating parallels in the regulation of content: Moving from offline to online. University of New South Wales Law Journal Forum, 16(1), 95-108.

Bitcoin. (2011). Bitcoin P2P Digital Currency. Retrieved from http://bitcoin.org and archived at http://www.webcitation.org/62jqFO2p8

Boase, J., \& Wellman, B. (2006). Personal relationships: On and off the internet. In A. Vangelisti \& D. Perlman (Eds.), Handbook of personal relationships (pp. 709-726). Cambridge, England: Cambridge University Press.

Bond, B., Hefner, V., \& Drogos, K. (2009). Information-seeking practices during the sexual development of lesbian, gay, and bisexual individuals: The influence and effects of coming out in a mediated environment. Sexuality and Culture, 13, 32-50.

Boyer, E. W., Shannon, M., \& Hibberd, P. L. (2005). The Internet and psychoactive substance use among innovative drug users. Pediatrics, 115, 302-305. 
Bretthauer, D. (2002). Open source software: A history. Information Technology and Libraries, 21, 3-10.

Bruns, A. (2006). Towards produsage: Futures for user-led content production. In F. Sudweeks, H. Hrachovec \& C. Ess (Eds.), Proceedings: Cultural attitudes towards communication and technology (pp. 275-284). Perth, Australia: Murdoch University.

Crawford, K., \& Lumby, C. (2011). The adaptive moment: A fresh approach to convergent media in Australia. Sydney, Australia: Journalism and Media Research Centre, University of New South Wales.

Diaz, J. (2011, March 11). It’s time to declare war against Apple’s censorship. Gizmodo (New York, USA). Retrieved from http://www.gizmodo.com.au/2010/03/its-time-todeclare-war-against-apples-censorship/ and archived at http://www.webcitation.org/5y24UEe2b

“Expert opinions”. (1997). Expert opinions: Ecstasy. ABC Quantum: Australia. Retrieved from http://www.abc.net.au/quantum/poison/ecstasy/shulgin.htm and archived at http://www.webcitation.org/5y1uGTgGA

Eysenbach, G. (2008). Medicine 2.0: Social networking, collaboration, participation, apomediation, and openness. Journal of Medical Internet Research, 10(3), e22.

Fallis, D. (2008). Toward an epistemology of Wikipedia. Journal of the American Society for Information Science and Technology, 59, 1662-1674.

Fynes-Clinton, M. (2009, March 31). Rogue chemist employs the internet to spread the word. Courier Mail (Brisbane, Australia). Retrieved from http://www.couriermail.com.au/news/features/uncle-festers-online-recipes/storyfn2mcu0g-1225698914326 and archived at http://www.webcitation.org/5yCHp6wzw 
Gascoigne, M., Dillon, P., \& Copeland, J. (2004). Sources of ecstasy information: Use and perceived credibility (NDARC Technical Report). Sydney, Australia: National Drug and Alcohol Research Centre.

Grim, R. (2010, August 24). Facebook blocks ads for pot legalization campaign. Huffington Post. Retrieved from http://www.huffingtonpost.com/2010/08/24/facebook-blocksads-for-p_n_692295.html and archived at http://www.webcitation.org/5y276DI8H

Halliday, J. (2012, April 19). Free speech haven or lawless cesspool - can the internet be civilised? The Guardian (London, England). Retrieved from http://www.guardian.co.uk/technology/2012/apr/19/free-speech-haven-lawlesscesspool and archived at http://www.webcitation.org/674qNh1Jl

Jaehrling, S. (Ed.). (2010). Banned books in Australia: A comprehensive survey of book censorship in Australia from settlement to the twenty-first century (2nd ed.). Melbourne, Australia: University of Melbourne Custom Book Centre.

Jenkins, P. (1999). Synthetic panics: The symbolic politics of designer drugs. New York, NY: University Press.

Johnston, J., Barratt, M. J., Fry, C. L., Kinner, S., Stoové, M., Degenhardt, L., et al. (2006). A survey of regular ecstasy users’ knowledge and practices around determining pill content and purity: Implications for policy and practice. International Journal of Drug Policy, 17, 464-472.

Koumartzis, N., \& Veglis, A. (2011). Internet regulation: The need for more transparent Internet filtering systems and improved measurement of public opinion on Internet filtering. First Monday, 16(10).

Leaning, M. (2009). The Internet, power and society: Rethinking the power of the Internet to change lives. Oxford, England: Woodhead Publishing Ltd. 
Lumby, C., Green, L., \& Hartley, J. (2009). Untangling the net: The scope of content caught by mandatory internet filtering. University of NSW, Edith Cowan University and the CCI ARC Centre of Excellence for Creative Industries and Innovation.

Murguía, E., Tackett-Gibson, M., \& Lessem, A. (Eds.). (2007). Real drugs in a virtual world: Drug discourse and community online. Lanham, MD: Lexington Books.

Murguía, E., Tackett-Gibson, M., \& Willard, R. (2007). Club drugs, online communities, and harm reduction websites on the Internet. In E. Murguía, M. Tackett-Gibson \& A. Lessem (Eds.), Real drugs in a virtual world: Drug discourse and community online (pp. 5-22). Lanham, MD: Lexington Books.

National Drug Research Institute. (2011). Public submission to the Australian Law Reform Commission National Classification Scheme review. Retrieved from http://www.alrc.gov.au/sites/default/files/pdfs/ci_1186a_national_drug_research_ins titute_curtin_university.pdf and archived at http://www.webcitation.org/642n4ZUOv

Ormsby, E. (2012, April 27). The drug’s in the mail. The Age (Melbourne, Australia). Retrieved from http://www.theage.com.au/victoria/the-drugs-in-the-mail-201204261xnth.html and archived at http://www.webcitation.org/67Dupfid1

Saunders, N. (1993). E for Ecstasy. London, England: Published by Nicholas Saunders.

Saunders, N. (1997). Australian censorship. New Australian seizure of Ecstasy Reconsidered. Retrieved from http://ecstasy.org/books/australia.html and archived at http://www.webcitation.org/5y1mj58J1

Shulgin, A. T., \& Shulgin, A. (1992). PIHKAL: Phenethylamines I have known and loved. Berkeley, CA: Transform Press. 
Tackett-Gibson, M. (2008). Constructions of risk and harm in online discussions of ketamine use. Addiction Research and Theory, 16, 245-257.

Taylor, J. (2012, March 29). Conroy plans filter ‘surprise’ announcement. ZDNet.com.au (Australia). Retrieved from http://www.zdnet.com.au/conroy-plans-filter-surpriseannouncement-339334877.htm and archived at http://www.webcitation.org/674o7xtAL

Tor Project. (2011). Tor Project. Anonymity online. Retrieved from https://www.torproject.org and archived at http://www.webcitation.org/62jq3Psag

Walsh, C. (2011). Drugs, the Internet and change. Journal of Psychoactive Drugs, 43, 55-63.

Wellman, B., \& Gulia, M. (1999). Virtual communities as communities: Net surfers don’t ride alone. In M. A. Smith \& P. Kollock (Eds.), Communities in cyberspace (pp. 167194). London, England: Routledge. 